\title{
Response of Different Strains of Enterococcus faecalis to UV Inactivation after Freezing
}

\author{
W. Gao and A. Williams
}

\begin{abstract}
Response of two strains of Enterococcus faecalis bacteria, ATCC strain 29212 and ATCC strain 51299 (vancomycin resistant) to $U V$ inactivation after survived freezing treatment was examined. The test microorganisms were frozen at $-7^{\circ} \mathrm{C},-15{ }^{\circ} \mathrm{C}$ or $-30{ }^{\circ} \mathrm{C}$ with one, three or five freeze and thaw cycles prior to $\mathrm{UV}$ irradiation to investigate the effect of freezing temperature and freeze thaw cycles on the efficacy of $U V$ inactivation. Experimental results suggest that freezing influenced the response of Enterococcus faecalis cells to UV irradiation. Freezing treated cells behaved differently compared to those had not frozen.
\end{abstract}

Index Terms-Enterococcus faecalis, freezing treatment, UV disinfection, waterborne pathogens, water and wastewater treatment.

\section{INTRODUCTION}

Conventional municipal wastewater treatment systems can significantly reduce the population of microorganisms; however, after treatment wastewater treatment plant (WWTP) effluents may still contain high numbers of fecal bacteria. Published research data indicated that the portion of pathogenic and antibiotic resistant bacteria in WWTP effluent remained at significant concentrations or even increase [1]-[5]. Release of pathogenic and antibiotic resistant microorganisms with WWTP effluents is a growing public health concern [6], [7]. Multiple antibiotic resistant fecal coliforms and enterococci including vancomycin resistant Enterococcus (VRE) have been detected in influent, effluent, and sludge from municipal wastewater treatment plants [8-9]. WWTPs provide a favorable environment for gene transfer due to high bacterial densities and nutritional richness of the influents [4], [8], [9]. Applications of UV disinfection in water and wastewater treatment systems have increased in recent years in Canada. Numerous research has been carried out to find the correlations between water quality, bacterial sensitivity and UV disinfection efficiency [10]-[12], the impact of cold temperatures on UV disinfection processes, especially, the responses of the pathogenic microorganisms after experiencing freezing to UV is however seldom examined [13], [14]. As a treatment alternative, natural or mechanical freezing has been used for various water or wastewater treatment, sludge pre-treatment or conditioning, and desalination [15]-[19]. Depending on the requirements of the finished water quality, UV disinfection may be needed after freezing treatment. Waterborne microorganisms might behave differently to UV

Manuscript received December 5, 2012; revised February 27, 2013.

W. Gao is with Department of Civil Engineering, Lakehead University, Thunder Bay, ON, Canada (e-mail: wagao@lakeheadu.ca). irradiation after survived freezing compared to those without experience freezing [13], [14], [20]. A recent study by Williams at al. [14] revealed that after freezing waterborne microorganisms such as Escherichia coli, Enterococcus and Bacillus behaved differently to UV irradiation compared to those had not frozen. Freezing affected the response of these microbes, a lower UV inactivation level was observed in the freezing treated bacteria in general. Furthermore, freezing also had an impact on the level of photoreactivation of Escherichia coli, Enterococcus following UV irradiation [21]. Obviously lower levels of photoreactivation were observed in the freezing treated E. coli and Enterococcus cells. The experimental results suggested that less photoreactivation could be expected if freezing is used as a treatment method prior to UV disinfection. The effect of freezing on the ability of the test microbes to photoreactivate seems to be strain and species dependent. This study was carried out to examine the response of two different strains of Enterococcus faecalis bacteria: ATCC strain 29212 and ATCC strain 51299 (vancomycin resistant) to UV inactivation after freezing under different temperatures with one, three or five freeze thaw cycles. Enterococcus faecalis was selected because they are one of the predominant species in water environment [22].

\section{MATERIALS AND METHODS}

\section{A. Test Microbes and Cell Solution Preparation}

The strains of $E$. faecalis bacteria used in this study were ATCC strain 29212 and ATCC strain 51299. Both of the $E$. faecalis strains are considered to be opportunistic pathogenic. The procedures used by [23] were followed for cell solution preparation. The ATCC strain 51299 was vancomycin resistant. Vancomycin (Sigma-Aldrich Inc., St. Louis, MD, USA) was added to the growth medium (TSB) of Enterococcus faecalis ATCC 51299 to a final concentration of $4 \mu \mathrm{g} / \mathrm{mL}$ to ensure that the resistance did not diminish. The cell solution concentration was approximately $1 \times 10^{8}$ $\mathrm{CFU} / \mathrm{mL}$.

\section{B. Freezing Treatment and UV Irradiation}

The same freezing treatments and UV inactivation procedures reported by [13] were used in this study. Two hundred $\mathrm{mL}$ of stock solution at room temperature $\left(20^{\circ} \mathrm{C}\right)$ were frozen at $-7{ }^{\circ} \mathrm{C},-15{ }^{\circ} \mathrm{C}$ or $-30{ }^{\circ} \mathrm{C}$ in a walk-in freezer (Climate Testing Systems Incorporated, Warminster, PA, USA). The temperature fluctuation for the freezer was \pm $0.5^{\circ} \mathrm{C}$. After freezing for 24 hours, samples were removed and thawed in a digital Isotemp 228 water bath (Fisher Scientific Ltd., Whitby, ON, Canada) set at $20^{\circ} \mathrm{C}$. It took 
about 1 hour for the samples to melt.

Once the samples completely melted, UV treatments started. Freeze thaw cycles of 1,3 and 5 were used to examine how repeated freezing and thawing could affect the response of the test microbes to UV irradiation. A UV collimated beam device with a low pressure mercury vapour lamp (monochromatic at $253.7 \mathrm{~nm}$ ) (Trojan Technologies, London, ON, Canada) was used as a UV source. UV fluences of $6,8,20$ and $25 \mathrm{~mJ} / \mathrm{cm}^{2}$ were used to get 1 to $4 \log$ reduction of cell concentration. More detailed information about the experimental setup could be found in [13]. Cells were frozen prior to UV inactivation and their response to UV inactivation was compared with those without freezing treatment. All experiments were replicated at least three times. The Log inactivation of the test microorganisms was calculated as:

$$
\text { Log inactivation }=\log _{10}\left(\frac{N}{N_{0}}\right)
$$

where $N_{0}=$ the concentration of microorganisms (in $\mathrm{CFU} / \mathrm{mL}$ ) of the non-irradiated sample, and $N=$ the concentration of microorganisms able to reproduce after irradiation.

\section{RESUlTS AND DISCUSSION}

Fig. 1 compares the average UV inactivation levels of the two strains of E. faecalis bateria that with and without freezing treatment (the controls). For the freezing treated cells, the data presented in Fig. 1 are the average values obtained by combining the data under all freezing temperatures and freeze thaw cycles. Freezing influenced the behavior of $E$. faecalis to UV inactivation. In general, lower $\log$ inactivation levels were observed in the freezing treated cells for both strains of $E$. faecalis compared to those had not frozen. After freezing E. faecalis cells became less sensitiy to UV irradiation. The control samples had about 0.3 to 0.4 more log inactivation than those freezing treated ones.

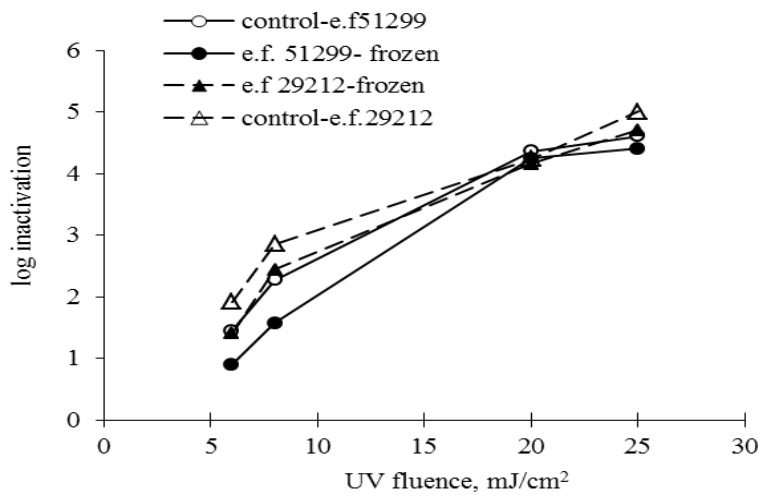

Fig. 1. Response of difference strains of E. faecalis to UV inactivation: comparison of the freezing treated samples with those without freezing (the controls).

Fig. 2 (a, b, c) illustrtes the log inactivation levels of the freezing treated $E$. faecalis obtained under a given temperautre and UV fluence in comparison to those of the controls. It was observed under all three freezing temperaure conditions that higher UV inactivation levels were obtained for the cells that had not frozen as comapred to the freezing treated ones, especailly at lower UV fluences (6 and 8 $\mathrm{mJ} / \mathrm{cm}^{2}$ ). Bewteen the two strains of E. faecalis, ATCC strain 51299 (vancomycin resistant) had samller differences in log inactivation levels between the control and the freezing treated ones in most cases except at $-30{ }^{\circ} \mathrm{C}$ while the reduction in UV inactivation level was slightly more noticeable in the freezing treated cells of ATCC strain 29212. Overall, the extent of reduction in UV inactivation efficiency seems varied with strain type, freezing temperature and UV fluences. As UV fluence increased, the difference between the control and the freezing treated cells or between the two strains became less noticeable. It is expected because cells would be killed after exposure to high strength of UV light whether or not they were pre-exposed to freezing.

(a)

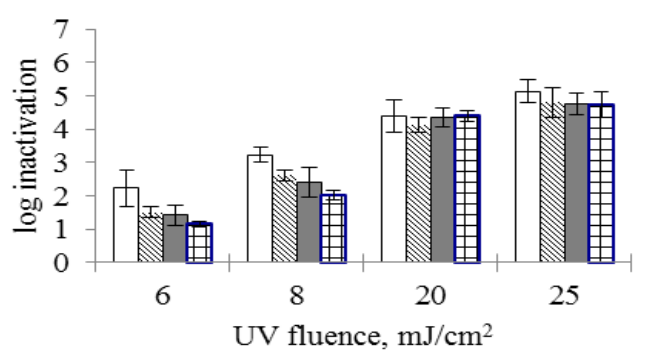

(b)
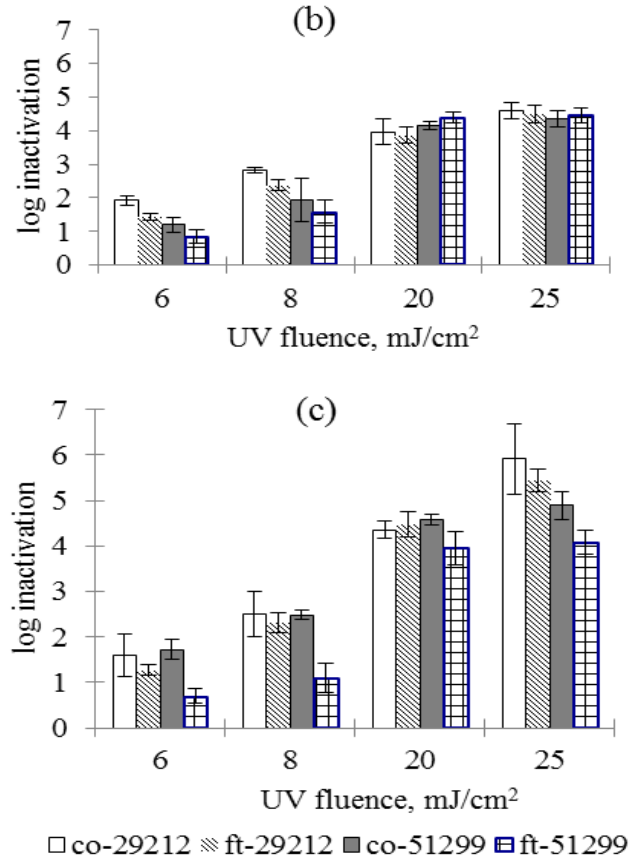

Fig. 2. Log inactivation levels of the freezing treated and nonfrozen $E$. faecalis cells under a given UV fluence and temperature: (a) freezing treated cells were frozen at $-7^{\circ} \mathrm{C}$, (b) freezing treated cells were frozen at $-15^{\circ} \mathrm{C}$, c) freezing treated cells were frozen at $-30^{\circ} \mathrm{C}(\mathrm{co}-29212=$ control of ATCC strain 2922; ft-29212 = freezing treated ATCC strain 29212; co-51299= control of ATCC strain 51299, ft-51299 = freezing treated ATCC strain 51299).

Table I summarizes the percentage decrease in the level of log inactivation of freezing treated samples compared to their corresponding control samples under a given freezing tempearture and UV fluence. For the ATCC strain 51299 (vancomycin resistant) of E. faecalis, the most obvious reduction in $\log$ inactivation level was observed at $\mathrm{UV}$ fluence of $6 \mathrm{~mJ} / \mathrm{cm}^{2}$ after frozen at $-30{ }^{\circ} \mathrm{C}$, there were $60 \%$ 
fewer freezing treated ATCC 51299 cells were inactivated comparted to the controls. It was not clear why ATCC strain 51299 cells frozen at $-30{ }^{\circ} \mathrm{C}$ were so resistant to UV inactivation. The most reduction in the UV inactivation level for the ATCC 29212 strain occurred after freezing at $-7^{\circ} \mathrm{C}$ followed with UV irridiation at fluence of $6 \mathrm{~mJ} / \mathrm{cm}^{2}$; the reudction in $\log$ inactivation level reached $32.3 \%$. If considering all UV fluences and freezing temperatures examined in this study, the average reduction in UV inactivation level after freezing was $8 \%$ to $16 \%$ for ATCC strain 29212 , and $8 \%$ to $36 \%$ for ATCC strain 51299 . Freezing temeprature alone had no obvious influence on the level of UV inactivation of the freezing treated cells. Cell frozen at $-7{ }^{\circ} \mathrm{C},-15{ }^{\circ} \mathrm{C}$ or $-30{ }^{\circ} \mathrm{C}$ all responded similarly to UV irridiation. Freeze thaw cycless as a factor also had no obvious impact on the UV inactivation levels of freezing treated cells.

TABLE I: \% REDUCTION IN LOG INACTIVATION OBSERVED IN THE FREEZING TREATEd CELLS CoMPaRED to THE CONTROL SAMPLES

\begin{tabular}{|c|l|l|l|l|l|l|}
\hline \multirow{2}{*}{$\begin{array}{l}\text { UV } \\
\text { Fluence } \\
\left(\mathrm{mJ} / \mathrm{cm}^{2}\right)\end{array}$} & \multicolumn{5}{|c|}{-7} & \multicolumn{2}{c|}{-15} \\
\cline { 2 - 7 } & ATCC & ATCC & ATCC & ATCC & ATCC & ATCC \\
& 29212 & 51299 & 29212 & 51299 & 29212 & 51299 \\
\hline 6 & 32.3 & 18.9 & 25.9 & 28.2 & 20.3 & 60.0 \\
\hline 8 & 19.3 & 15.6 & 15.7 & 18.6 & 7.7 & 55.6 \\
\hline 20 & 6.1 & -1.2 & 2.4 & -5.5 & -2.9 & 13.7 \\
\hline 25 & 6.5 & 0.3 & 2.2 & -2.9 & 8.0 & 16.5 \\
\hline
\end{tabular}

\section{CONCLUSION}

Freezing influenced the response of both ATCC strain 29212 and ATCC strain 51299 (vancomycin resistant) of $E$. faecalis cells to UV irradiation. Overall E. faecalis bacteria became less sensitive to UV inactivation after freezing. The effect of freezing on the response of E. faecalis to UV seems to be strain dependent. UV inactivation effect was reduced significantly under certain conditions after E. faecalis cells survived freezing. No significant difference in UV inactivation was observed for the cells frozen at $-7{ }^{\circ} \mathrm{C},-15^{\circ} \mathrm{C}$ or $-30^{\circ} \mathrm{C}$. Freeze thaw cycles $(1,3,5)$ also had no obvious effect on the response of freezing treated cells to UV. The most noticeable reduction in the log inactivation level between the control (without freezing) and the freezing treated cells occurred at the lower UV fluence $\left(6 \mathrm{~mJ} / \mathrm{cm}^{2}\right)$.

\section{ACKNOWLEDGMENT}

The authors wish to acknowledge the National Science and Engineering Research Council of Canada for financial support.

\section{REFERENCES}

[1] L. Guardabassi, D. M. A L. F. Wong, and A. Dalsgaard, "The effect of tertiary wastewater treatment on the prevalence of antimicrobial resistant bacteria ," Wat. Res., vol. 36, pp. 1955-1964, 2002.

[2] J. Koivunen, A. Siitonen, and H. H. Tanski, "Elimination of enteric bacteria in biological-chemical wastewater treatment and tertiary filtration units ," Wat. Res., vol. 37, pp. 690-698, 2003.

[3] G. D. Re, A. Donato, R. Volpe, and C. Pellegrini, "Urban wastewater reuse: a pilot plant experience," Int. J. Env. Tech. Mangement, vol. 7 , no. 1-2, pp. 3-20, 2007.

[4] M. Silva, I. Tiago, A. Verissimo, R. Boaventura, O. Nunes, and C. Manaia, "Antibiotic resistance of enterococci and related bacteria in an urban wastewater treatment plant," FEMS, vol. 55, pp. 322-329, 2005.
[5] R. Rajiala, M. Pulkkannen, M. Pessi, H. Heinonen-Tanski, "Removal of microbes from municipal wastewater effluent by rapid sand filtration and subsequent UV irradiation," Wat. Sci. Techno., vol. 47, no. 3, pp. 157-162, 2003.

[6] I. George, P. Crop, and P. Servais, "Fecal coliform removal in wastewater treatment plants studied by plate counts and enzymatic methods," Wat. Res., 36: 2607-2617, 2002.

[7] F. Reinthaler, J. Posch, G. Feieri, G. Wüst, D. Haas, G. Ruckenbauer, F. Mascher, and E. Marth, "Antibiotic resistance of E. coli in sewage and sludge ," Wat. Res., vol. 37, pp. 1685-1690, 2003.

[8] J. Xu, C. Gallert, and J. Winter, "Multiple antibiotic resistances of Enterococcus isolates from raw or sand-filtered sewage," Appl. Micro. Biotech., vol. 74, pp. 493-500, 2007.

[9] P. de Costa, P. Vaz-Pires, and F. Bernardo, "Antimicrobial resistance in Enterococcus spp. Isolated in inflow, effluent and sludge from municipal sewage water treatment plants ,"Wat. Res., vol. 40, pp. 1735-1740, 2006.

[10] A. M. Shaban, G. E. E. Taweel, and G. H. Ali, "UV ability to inactivate microorganisms combined with factors affecting radiation," Wat. Sci. Techno., vol. 35, no. 11-12, pp. 107-112, 1997.

[11] L. F. Batch, C. R. Schulz, and K. G. Linden, "Evaluating water quality effects on UV disinfection of MS2 coliphage". J. $A W W A$, vol. 96, no. 7, pp. 75-87, 2004.

[12] H. M. Gravetz and K. G. Linden, "Relationship between physiochemical properties, aggregation and u.v. inactivation of isolated indigenous spores in water ," J. Appli. Microbio., vol. 98, pp. 351-363, 2005.

[13] A, Williams, W. Gao, and K. Leung, "Effects of freezing on UV inactivation of waterborne microorganisms , Journal of Env. Eng., vol. 138, no. 4, pp. 470-474, 2011.

[14] W. Gao, D. Smith, Y. Li, "The effects of freezing on the survival of $E$ coli and Bacillus and the response to UV and chlorine after freezing". Wat. Env. Res., vol. 79, no. 5, pp. 507-513, 2007.

[15] A. Attia, "New proposed system for freeze water desalination using auto reversed R-22 vapor compression heat pump," Desa., vol. 254, pp. 179-184, 2010.

[16] W. Gao, D. Smith, and Y. Li "Natural freezing as a wastewater treatment method: E.coli inactivation capacity". Wat. Res., vol. 40, no. 12, pp. 2321-2326, 2006.

[17] W. Gao and Y. Shao, "Freeze concentration for removal of pharmaceutically active compounds in water," Desa, vol. 249, pp. 398-402, 2009.

[18] B. Örmeci, and P. Vesilind, "Effect of dissolved organic material and cations on freeze-thaw conditioning of activated and alum sludges," Wat. Res., vol. 35, no. 18, pp. 4299-4306, 2001.

[19] W. Gao, "Freezing as a combined wastewater sludge pretreatment and conditioning method," Desa., vol. 268, pp. 170-173, 2011.

[20] N. Nwachuku, C. P. Gerba, A. Owald, and F. D. Mashadi, "Comparative inactivation of adenovirus serotypes by UV light disinfection," Appl. Environ. Microbiol., vol. 71, pp. 5633-5636, 2005.

[21] A. Williams, W. Gao, and K. Leung, "Effect of Freezing on Photoreactivation of Escherichia coli and Enterococcus faecalis ," Wat. Env. Res., vol. 84, no. 6, pp. 529-534, 2012.

[22] Š. Cupáková, and J. Lukášová, "Agriculturcal and Municipal Waste Water as a Source of Antibiotic-resistant Enterococci ," Acta Vet. Brno, vol. 72, pp. 123-129, 2003.

[23] W. Gao, K. Leung, and N. Hawdon, "Freeze inactivation of Escherichia coli and Enterociccus faecalis in water: Response of different strains ," Wat. Env. Res., vol. 81, no. 8, pp. 824-830, 2009.

Wa Gao is a professor at the Department of Civil Engineering, Lakehead University, 955 Oliver Road, Thunder Bay, Ontario, Canada, P7B 5E1.

Dr. Gao holds a $\mathrm{PhD}$ in environmental engineering from the University of Alberta, Edmonton, Alberta, Canada. Dr. Gao's has conducted research in the areas such as water and wastewater treatment, cold temperature impacts on water/wastewater treatment processes, freezing technology and applications in water treatment, and pretreatment of wastewater sludge. Dr. Gao has been published previously in peer reviewed journals in environmental engineering such as Water Research, Journal of Environmental Engineering, and Desalination. Dr. Gao is a member of American Water Works Association (AWWA) and International Water Association (IWA) and Canadian Association on Water Quality (CAWQ).

Andrea William is an environmental scientist with KGB group, Thunder Bay, Ontario, graduated with a M.Sc. degree in environmental engineering from Lakehead University, Thunder Bay, Ontario, Canada. 